\title{
Patients' and family caregivers' experiences and perceptions about factors hampering or facilitating patient empowerment for self-management of hypertension and diabetes in Cameroon: Evidence from thematic and lexicometric analyses of qualitative study data
}

Amélie Mogueo

University of Montreal

BARTHELEMY KUATE DEFO ( $\sim$ barthelemy.kuate.defo@umontreal.ca ) University of Montreal

\section{Research Article}

Keywords: Patient empowerment, self-management, noncommunicable diseases, hypertension, diabetes, healthcare delivery, barriers, facilitators, qualitative methods, Africa

Posted Date: October 15th, 2021

DOl: https://doi.org/10.21203/rs.3.rs-952885/v1

License: (c) (i) This work is licensed under a Creative Commons Attribution 4.0 International License. Read Full License 
Title:

Patients' and family caregivers' experiences and perceptions about factors hampering or facilitating patient empowerment for self-management of hypertension and diabetes in Cameroon:

Evidence from thematic and lexicometric analyses of qualitative study data

Running title:

Patients' and caregivers' experiences and perceptions about patient empowerment in Cameroon

\section{Amélie Mogueo ${ }^{1,2}$, Barthelemy Kuate Defo ${ }^{1,2,3,4, *}$}

${ }^{1}$ Programme en Population, Nutrition et Une-Santé Transnationales, Infranationales, Nationales et Continentales (PRONUSTIC) / Program in Transnational, Subnational, National and Continental Population, Nutrition and One-Health (PRONUSTIC), University of Montreal, Montreal (Quebec), H3T 1N8, Canada

${ }^{2}$ Department of social and preventive medicine, School of public health, University of Montreal, 7101 Avenue du Parc, Montreal (Quebec), H3N 1X9, Canada

${ }^{3}$ Department of demography, University of Montreal, Pavillon Lionel-Groulx, C. P. 6128, succursale Centreville, Montreal (Quebec), H3C 3J7, Canada

${ }^{4}$ Public Health Research Center (CReSP), University of Montreal, 7101 Avenue du Parc, C.P. 6128 Succursale Centre-Ville, Montreal (Quebec), H3C 3J7, Canada

\section{* Corresponding author:}

Professor Barthelemy Kuate Defo, Director, Programme en Population, Nutrition et Une-Santé Transnationales, Infranationales, Nationales et Continentales (PRONUSTIC) / Program in Transnational, Subnational, National and Continental Population, Nutrition and One-Health (PRONUSTIC), University of Montreal, Montreal (Quebec), H3T 1N8, Canada. E-mail address: barthelemy.kuate.defo@umontreal.ca. 


\section{Abstract (350; $\max =350$ words)}

\section{Background}

Noncommunicable diseases like hypertension and diabetes require long-term management, and are financially draining for patients and their families bearing the treatment costs, especially in settings where the inadequacy or non-existence of the health insurance system prevails. Patient empowerment-focused interventions have been shown to improve adherence to therapeutic regimens and decrease unnecessary health care utilization and costs. This study aims to examine enabling and impeding factors to the development of patient empowerment in a resource-limited setting like Cameroon.

\section{Methods}

We used qualitative methods entailing three levels of investigation and involving a public primary healthcare hospital in Yaoundé, Cameroon. Data were collected through 40 semi-structural interviews with patients having hypertension or diabetes and their family caregivers, one focus group discussion with six patients, 29 observations of consultations of patients by specialist physicians, seven observations of care received by inpatients from generalist physicians, and nine documents on the management of hypertension or diabetes. A novel approach combining thematic and lexicometric analyses was used to identify similarities and differences in barriers and facilitators associated with patient empowerment at different levels of the healthcare delivery system in Cameroon.

\section{Results}

Barriers generally outnumbered facilitators. There were particularities as well as commonalities in reported facilitators and barriers linked to patient empowerment from different experiences and perspectives of outpatients, inpatients and their family caregivers, given the healthcare services and organization of health personal and resources that deliver healthcare services to meet the health needs of patients with hypertension 
or diabetes in Cameroon. While specific factors identified by patients were directly related to the selfmanagement of their disease at the individual level, family caregivers were mainly focused on factors present at organizational and central levels, which are indirectly related to the management of the diseases and beyond the control of patients and families.

\section{Conclusions}

The preponderance of individual-level factors linked to patient empowerment more than those at the central and hospital/organizational levels calls for due attention to them in the multilevel design and implementation of patient empowerment interventions in resource-limited settings like Cameroon. Accounting for patient's and families' perspectives and opinions may be key to improving healthcare delivery.

\section{Key words}

Patient empowerment, self-management, noncommunicable diseases, hypertension, diabetes, healthcare delivery, barriers, facilitators, qualitative methods, Africa 


\section{INTRODUCTION}

The global disability-adjusted-life-years (DALYs) from noncommunicable diseases (NCDs) startlingly increased by $41.1 \%$ between 1990 and 2017 [1]. This increase is driven by the rapidly growing burden of NCDs in low- and middle-income countries (LMICs), especially hypertension and type 2 diabetes which are among the leading causes of morbidity, mortality, and reduced life expectancy worldwide, especially in African countries like Cameroon [2]. This study focuses jointly on hypertension and diabetes because they are known to coexist in the population; their coexistence confers a dramatically increased risk (about 2-4 fold) of cardiovascular disease, end-stage kidney disease, and death, compared to the normotensive and nondiabetic adults [3]. Moreover, the pathogenic relationship between hypertension and diabetes is bidirectional, their prevalence increases with increasing age [4-5], and adequate control of blood pressure significantly reduces the risk of diabetic macrovascular and microvascular complications [6]. The prevalence of hypertension and diabetes in Cameroon is estimated at 32.1\% [7] and 5.8\% [8], respectively. Hypertension and diabetes are long-term management diseases financially draining for patients and their families in Africa and Cameroon notably, given the inadequate or non-existence of a health insurance system [9-10]. This has resulted in a high prevalence of patients being non-adherent to therapeutic plans. Thus, there is an urgent need to implement cost-effective patient-based interventions that empower patients to control and manage their own disease, following the World Health Organization's framework on integrated, people-centred health services, which emphasizes the importance of organizing primary health care around comprehensive needs of people, rather than around a singular focus of specific diseases [11].

Patient empowerment (PE) has gained prominence in the healthcare system, emerging as one of the general principles of the World Health Organization's global action plan for the prevention and control of NCDs 2013-2020 [12]. A PE approach sees the patient as an actor of care, who can participate in care decision-making process, develop competency, self-manage his condition, and contribute to continuous improvement in the quality of healthcare delivery. Interventions based on PE or self-management in NCDs 
has been shown to improve a variety of important health outcomes [13], including adherence to therapeutic plans and decreased unnecessary health care utilization and costs in every health care system [14-17]. The PE approach requires contextualized innovative disease management strategies. Implementation research shows that interventions based on PE face generally barriers that need to be identified to optimize its use, as perceived by different groups of key stakeholders such as patients and their families, health professionals and policy makers [18-20]. Research on patients and families' perceptions and experiences about factors facilitating or hampering the development of PE remains scanty in resource-limited settings [16-17, 21].

This study aimed to pinpoint influential factors associated with the development of PE in the primary healthcare context of Cameroon, often considered as a microcosm of Africa [7]. Exploring these factors systematically may help policymakers and clinicians in identifying and understanding both facilitators and barriers to empowerment of patients and in tailoring interventions to the identified factors. Given the rising multimorbidity of chronic diseases in primary care and its effect on healthcare utilization and costs worldwide, this study will contribute to inform future interventions to remove barriers to and creating a facilitating environment for PE in the healthcare systems in sub-Saharan Africa for NCDs and the management of hypertension and diabetes.

\section{METHODS}

\section{Conceptual framework}

Defined as "a process through which people gain greater control over decisions and actions affecting their health" [22: 190], PE has been influenced by several theories of health behaviour change [23-25], particularly the salutogenic theory proposed by Antonovsky [26]. We adopted an integrated framework (Figure 1) to aid data collection, analysis, and presentation of findings. This framework links the salutogenic theory [26-27] to the health belief model [28-29] and patient satisfaction theory [30-32].

[Insert Figure 1 about here] 
The salutogenic theory summarizes the PE approach into two main concepts: sense of coherence (SOC) embodied by intelligibility, manageability, meaningfulness; and generalized resistance resources (GRR) embodied by internal and external resources [26]. It suggests that to be empowered and have better health outcome, a patient need to develop a strong intelligibility, manageability, meaningfulness (SOC) with available internal and external resources (GRR). Thus, SOC refers to a patient's capability to use existing resources (GRR) to understand factors affecting their health (intelligibility), to be able to better manage the diseases (manageability) and to looking at life as worth living (meaningfulness). A stronger SOC is predictive of salutogenesis (or production of health) [27]. The GRR are prerequisites to develop a stronger SOC [26-27].

The salutogenic theory summarizes the PE approach in two concepts: sense of coherence (SOC) embodied by intelligibility, manageability, meaningfulness; and generalized resistance resources (GRR) represented by resources. To be empowered and have better health outcome, patients need to develop a strong intelligibility, manageability, meaningfulness (SOC) with available internal and external resources (GRR). SOC refers to patients' capability to use existing resources (GRR) to understand factors affecting their health (intelligibility), to be better able to manage their diseases (manageability) and to look at life as worth living (meaningfulness) [26-27]. A stronger SOC is predictive of salutogenesis (i.e. production of health). GRR are prerequisites to develop a stronger SOC.

Our framework recognizes that PE axes not only on patient's SOC and available GRR, but also on patient belief [28-29] and patient satisfaction [30-32]. Indeed, patients' beliefs influence their perceptions and experiences of their disease. Personal beliefs influence the understanding of the disease (intelligibility), daily actions taken to manage the disease (manageability), and motivations behind each choice (meaningfulness). Patients' satisfaction as a positive evaluation of healthcare services means that the more patients are satisfied, the more they will adhere to treatment and hence develop the ability to self-manage their disease and viceversa (manageability). Patients' satisfaction also influences their motivation to self-manage their diseases and 
to make sense of the process (meaningfulness). Therefore, patients' beliefs and satisfaction influence the SOC (intelligibility, manageability, meaningfulness), and its integration with existing resources (GRR) used by patients. Thus, improving the different components of health behavioral change as depicted in our framework may improve patients' adherence to treatment and ultimately improve health outcomes. Improved health outcomes may in turn be a source of motivation for people to maintain change, which may reduce the utilization of health care services.

\section{Study design and setting}

We use qualitative methods within a 3-level healthcare system: patient-level, hospital-level, and central/Ministry-level. Patients were recruited in Yaounde (Cameroon) at a primary healthcare district hospital (PHCDH). The $\mathrm{PHCH}$ at the peripheral level within the health system in Cameroon is where patient healthcare is operationalized, in line with the health district framework proposed by the World Health Organization [33]. This PHCDH is the first reference for 11 health centres and patients' gateway to the healthcare system. It included the internal medicine unit having a team of six nurses, two general practitioners (GP), and four specialist physicians (SP), for patients suffering from hypertension/diabetes.

\section{Participants}

We recruited patients with hypertension/diabetes who met our inclusion criteria, and their family caregiver (FC). Eligibility criteria were: had hypertension and/or diabetes for at least 12 months, be hospitalized or followed-up at the selected PHCDH for at least 12 months, and be aged 30 years or older. Pregnant women were excluded. Enrolled patients facilitated access to FC. Hypertension (HTN) was defined as systolic blood pressure (BP)/diastolic BP $\geq 140 / 90 \mathrm{~mm} \mathrm{Hg}$. Type 2 diabetes (T2D) was defined as high levels of blood glucose (Glycated hemoglobin (A1C) $\geq 6.5 \%$ or fasting plasma glucose (FPG) $\geq 126 \mathrm{mg} / \mathrm{dl}$ or oral glucose tolerance test $($ OGTT $) \geq 200 \mathrm{mg} / \mathrm{dl})$. 


\section{Data collection}

Prior to data collection, we piloted and refined survey instruments based on two 40-minutes interviews with patients and clinic observations. Interviews were recorded and the two authors independently listened to recorded data, checked transcripts for validation, and adjusted interview procedures to better fit our study context. For example, we found that participants' knowledge about patient empowerment was deficient and decided to explain it.

Data were collected from 07 January to 29 March 2019, through 40 semi-structural interviews, one focus group discussion (FGD), 29 observations of consultations of patients by SP, seven observations of care received by hospitalized patients from GP, nine documents, and field notes. Each interview was conducted at a calm space in the hospital away from other people. One author conducted all interviews using interview guides (Additional file 1), and deliberated with the other author when significant decisions had to be made. The FGD involved six patients previously interviewed individually who agreed to participate. Interviews lasted 20 to 50 minutes and the FGD took 60 minutes. Interviews and FGD were audiotaped and transcribed by one author. The other author independently read all transcripts with corresponding audiotapes, and found no discrepancies.

Direct and passive observations, for 10 to 30 minutes, of consultations of patients took place in SP offices and patients' hospitalization rooms. We observed interactions between participants and healthcare professionals and took detailed notes. Documents reviewed were health education $(n=3)$, healthcare services for patients $(n=2)$, and national policies/programs on hypertension/diabetes management $(n=4)$.

\section{Data analysis}

All transcripts and field notes were imported into the software package Qualitative Data Analysis (QDA) Miner [34]. Interview data were thematically analyzed by the two authors. We used an initial coding list based on our integrated framework, allowing themes to emerge [35]. To check for consistency, data sources 
were triangulated by seeking different data sources in the study, and by crosschecking different points of view of stakeholders [36]. Findings from different sources and methods used led to concordant findings.

The IRaMuTeQ software was used to perform the lexicometric analysis [37], including a word cloud and similarity analysis [38]. The word cloud analysis displays the lexicon of words associated with the corpus in the form of a graph where the size of the words is proportional to their frequency. The similarity analysis allows a co-occurrence analysis presented in the form of graphs of associated words. The words are the vertices of the graph, and the links represent the co-occurrences between these words.

\section{RESULTS}

\section{Characteristics of participants}

The study involved 40 participants (Table 1). Of the 23 patients, $74 \%$ were female; $69.6 \%$ aged 60 years or older; $34.8 \%$ having hypertension only (HTN), 26.1\% having type 2 diabetes only (T2D), and 39.1\% having both HTN-T2D; 78.3\% outpatients; and 56.5\% living with their disease(s) for five years or more. Among the 17 FCs, $70.6 \%$ were female; $17.6 \%$ under 30 years; $23.5 \%, 35.3 \%$, and $41.2 \%$ of them were caring for patients having HTN, T2D, and HTN-T2D, respectively; $29.4 \%$ caring for inpatients; $35.3 \%$ caring for patients living with their disease for five years or more; and $17.7 \%$ were patients' wives, while no patient's husband was FC despite $60.9 \%$ of patients being currently married.

[Insert Table 1 about here]

\section{Patients' and family caregivers' experiences and perspectives}

There were 53 barriers (Additional file 2): 4 at the central level: intelligibility (2), manageability (1), external resources (1); 19 at the hospital/organizational level: intelligibility (3), manageability (4), meaningfulness (1), external resources (9), satisfaction (2); 30 at the individual/patient/FC level: intelligibility (5), manageability (5), meaningfulness (4), internal resources (2), external resources (2), adherence and health outcomes (7), belief (5). 
We identified 41 facilitators (Additional file 3): 2 at the central level: intelligibility (1) and manageability (1); 12 at the hospital/organizational level: intelligibility (3), manageability (2), internal resources (1), external resources (2), adherence and health outcomes (1), satisfaction (3); 27 at the individual/patient/FC level: intelligibility (7), manageability (4), meaningfulness (5), internal resources (3), external resources (5), adherence and health outcomes (1), belief (1), satisfaction (1).

\section{Intelligibility}

The top twelve words used to describe intelligibility were: know, tell, doctor, hospital, eat, time, blood, understand, disease, pressure, think and person (Figure 2). Patients' and family caregivers' knowledge or information seeking were mainly related to the doctor, hospital, lifestyle (diet/eat), disease control (blood sugar/pressure). The health information access was possible mainly through communication (tell) with the healthcare provider (doctor) (Figure 3).

[Insert Figure 2 and Figure 3 here]

Counselling and screening campaigns on NCDs organized by the ministry of health were viewed as limited and not supported by concrete actions helpful to patients.

"... The government needs to talk more about it in neighborhood churches and meetings... They have to send the text messages in our phone...We don't need the advice only when we come to the hospital." (FC2)

The patient education and counseling (PEC) for patients suffering from diabetes and consultations with SP were main channels for accessing information.

“... When we come here, we are asked ...to be active...I think organizing a service like that is good... help you know your body and know how and what to do to take care of it..." (P11)

The PEC was inaccessible to patients with hypertension and also to FCs.

'No, I'm not aware of that... I haven't been told about it since I've been here ... every time when we arrive, we see the doctor and we left..." (P5) 
Some FCs reported that physicians did not explain well the treatment plan, which sometimes caused confusion and discomfort to patients and caregivers.

“... The doctor had asked for the first time that she had to do the sport. We understood sport like bring her to a gym ... we registered her in a gym and paid... and she got sick after she left to a single session..." (FC5)

The most educated patients were more active in seeking information about the disease. Yet, the information-seeking process generally began once the disease was diagnosed.

“...I myself do a research, I surf on the internet; it helps me know how I should behave, what I have to eat, what I should not eat, what to do to avoid this or that ... this's how I live then now." (P7)

Older and less educated patients knew little about these practices, and thought it was the physician's responsibility. As most of their FCs were younger and more educated, they helped them communicate with physicians to properly identify their needs and propose a suitable treatment plan.

“... Well, for my mother..., she must follow-up her diet, take her medications because she is 75 years old, ... She can't submit to intense sport as us, her sport can be walking from time to time." (FC14)

\section{Manageability}

The top twelve words used to describe manageability were: eat, like, tell, time, walk, know, see, doctor, vegetable, good, sport and home (Figure 4). The healthy lifestyle, especially the diet (eat) and physical activity (walk), was the most challenging thing for patients and family caregivers as it was associated with comfort/discomfort (like), understanding/misunderstanding (know), and required times and money to have access to a variety of healthy foods (vegetables). The relationship with the healthcare provider (doctor) was also pointed out mainly through the communication (tell) (Figure 5).

[Insert Figure 4 and 5 here]

Waiting time was a major barrier highlighted chiefly by FCs of patients with diabetes or both diseases, many of whom had hypoglycemia after several hours of waiting. 
“... But if from 9am, she finally sees the doctor around 2pm it is not easy... I don't know how they are organized...sometimes we arrive we put our notebooks and they reverse everything, the first become the last." (FC4)

The quality of reception was also identified as a barrier. A mother's FC recounted:

"... She told me today that based only on the quality of the reception, before she sees the doctor, she would have already left the hospital..." (FC13)

The lack of control by the hospital management often led to illegal transactions of medicines, a major barrier for patient empowerment.

“... We don't want nurses to tell you to buy the drugs they have. They tell you, come I have drugs you want while you want to go to a pharmacy... So, we don't want corruption here.... It's not good like that." (FC14)

Being follow-up by SPs was a facilitator of patient empowerment.

"... She comes frequently... in addition to the diet to which she is subjected...she's well followed here." (FC12)

The trusted patient-physician interaction also facilitated adherence to recommended lifestyle and treatment.

"This Doctor has been my doctor for 5 years... he listens, and he gives advices... he explains very well..." (P2)

Sedentary lifestyle was a barrier identified by patients.

"I'm at my daughter's house...I get up in the morning they give me food, during the day they give, in the evening they give, so when I am not eating, I am sleeping. I do not work anywhere.” (P8)

For patients with hypertension, self-management of their disease was hampered by stressful financial and familial conditions knotted with out-of-pocket medical expenditures. For patients with diabetes, changing 
eating habits to healthy diet was a barrier. For patients with both diseases, late diagnosis hindered selfmanagement of disease.

"I feel like it's diabetes that causes other diseases, because I have many problems..." (P15)

Women were more actively involved in self-managing their disease than men.

"I asked my children to set up an alarm...to take the medication. When I hear the ring, I know this is the time to take my medicine..." (P19)

\section{Meaningfulness}

The top twelve words used to describe meaningfulness were: person, doctor, good, time, welcome, hospital, God, reception, receive, feel, long and help (Figure 6). The patients' motivation to be empowered so as to follow the treatment plan was mainly related to the family or neighborhood (person), the reception (good) and the relationship of trust with the healthcare provider (doctor) and the personal belief of patient (God) (Figure 7).

\section{[Insert Figure 6 and 7 here]}

Some healthcare professionals instilled more fear than confidence in patients by focusing more on consequences of their disease, a barrier for patients who felt powerless against their disease.

"He ... told me I have to take the medicines until I die, and I'm really scared for my case." (P16)

Trusted relationships between healthcare professionals and patients reassured the latter that their health will improve.

“... I really believe in the healing process ... Me I saw a great improvement, as I came last week Thursday for my result. I went to apply to really see how it works .... the thing $(B S)$ drops down from 2.41 to 1.15." (P21)

Patients' motivation to manage their diseases was negatively impacted by their perspective that there was no solution against diabetes, especially after a relative's death like interviewed widows living with these diseases or whose husbands died of hypertension, diabetes or their complications. 
“... I just lost my husband... and my BS and BP have started to rise again... I have no reason to keep fighting for life.” (P1)

Being positive helped some patients develop empowerment to improve their health outcomes. One FC recounted:

"She has no worries, she has no problem, she says to herself: if in the village there are thousands of people living with even HIV/AIDS, ... and are OK with the situation, why not her. It is both incurable diseases... It is like that; there are other people who are in a worse situation, she is really OK with her disease, and she handles it like that." (FC4)

\section{Resources}

The top twelve words used to describe manageability were: child, help, medicine, money, pay, give, daughter, buy, time, work, eat and home (Figure 8). As patients were mainly older people, the most important resource for them was their children caring for them and providing different types of support, including financial (money, pay, buy), physical (work), material (medicine) and immaterial/moral (come, time) (Figure 9).

[Insert Figure 8 and 9 here]

Some devices were not always available when needed, being shared among several healthcare units. Being overused, they often failed to work during the consultation.

"... What bothers me here is that, sometimes they say that there is not the machines to measure her BS and BP... sometimes the nurse can be measuring your BP and someone else comes and takes the device." (FC2)

The limited/small rooms for PEC and the reception were barriers for FCs and often deterred their involvement in their patients' follow-ups.

“... The size of the reception area, the consultation offices, the hospitalization room, the space for patient education are small according to the numbers of patients ..." (FC17) 
Medications and tests were usually out of stock, which affected adherence to treatment.

“... Her hypertension medicines became rare and we searched for almost two months and couldn't find anywhere... when we came back to see her doctor ... she prescribed another medicine ... There's often when you arrive the product to measure BS is out of stock in the hospital..." (FC8)

The presence of several SPs facilitated PE and FCs who appreciated the subsidy of certain products and services, and reported good follow-ups.

"I've been here since $2002 \ldots$ This is my 3rd patient book ...I'm here ...every month.” (P10)

Patients reported being financially sole responsible for their disease as a barrier to treatment adherence.

“... I'm a dad of a few children and alone... I've been hospitalized for quite a while and the drugs and exams and everything ... is looking for me... you have to change the lifestyle, the diet to get back in shape .." (P9)

Having a family or community support was a facilitator of treatment adherence.

“...neighbours are supportive enough to help her take care of herself... sometimes she forgets to take her medication, her nearest neighbour reminds her, recommends her vegetables and encourage her to eat." (FC14)

\section{Belief}

Believing that their disease is incurable, caused by spiritual forces, or from a curse, hindered patients' treatment adherence.

“... I think that if the disease comes, you're going to die with that, there's no solution... It's for life because even my father suffered from this until his last day." (P16)

"...I am believing that there is a person who is the cause of my disease.... I think bad spiritual forces have fallen on me, I'm the unlucky one to take that disease." (P6)

In contrast, believing in God was empowering for patients. 
“... I thank God...people will give glory to God about my illness in this hospital... all my fears disappeared...”(P21)

\section{Satisfaction}

Patient-SP interactions contributed to patient satisfaction.

“... My doctor is a smiling, welcoming young guy,..., if he wants to examine me, he gives me the courage..." (P9)

Finding satisfaction with life was empowering for some patients' adherence to treatment.

"...She wants to live for herself, for her children, her grandchildren and her great-grandchildren... she herself knows that she is needed and that's why...she's taking these drugs." (FC4)

\section{DISCUSSION}

The purpose of this study was to uncover, from participants' experiences and perspectives, barriers and facilitators associated with patient empowerment for self-managing hypertension and/or diabetes.

The misalignment of strategies adopted at the central/ministry level of the healthcare system with the management of the disease at the organizational/hospital level and the socioeconomic conditions of patients were the greatest impediments to patient empowerment. The funding constraints and hierarchical bureaucratic structure of the healthcare system in Cameroon, characterized by a high degree of centralized lines of control and complex administrative procedures, were major obstacles to the development process of PE. Similar findings were reported elsewhere in Africa [39-40] and agreed others which identified the bureaucratic top-down structure as barriers to effective implementation of PE strategies for chronic NCDs $[41-42]$

The main facilitator at the hospital/organizational level was the patient education counselling with different products and services to educate and follow-up patients with hypertension and diabetes. But the time accorded to each patient by some healthcare providers was not enough to share information about the 
disease and associated factors that can increase a patient's desire and ability to participate in the decisionmaking process, as also found elsewhere [41, 43].

FCs played an active role in the development of patient empowerment by seeking information about their diseases and recommended treatment. This role is under appreciated in the framework of chronic care model and self-management of NCDs in resource-limited settings [44-45]. Patients make best decisions when equipped with accurate and clearly communicated information with available space to explore options and choices [46].

The healthcare delivery at the hospital was hampered by long waiting times to see a specialist, the poor quality of service and overuse of some devices [45]. Poor management and leadership in healthcare as well as the context of care often led to corruption, disrespect, command, or mistreatment of patients and their families in the hospital system. Similar findings have been reported elsewhere in Africa [16, 47]. Healthcare professionals being key contact points between patients-families and healthcare systems, they often caused patient disempowerment as other studies have found [48-49].

The frequency of follow-up and the quality of patient-specialist interaction emerged as empowering for patients, as found in other LMIC settings [45]. Unfortunately, the hospital healthcare in Cameroon remains largely an acute care model with perceived staff shortages and ineffective communication, undermining the potential empowerment of patient and FCs. The relationship between patients/FCs and healthcare professionals should be more frequent with a reciprocal process of mutual respect for each person's knowledge and the right to make informed choices [49-50], in a partnership approach seeking to balance clinician's expertise with patients'/FCs' preferences. Available evidence suggests that health outcomes are better when patients are more involved in decisions about their treatment $[46,48,51]$.

The fear created by some healthcare professionals about the consequences of the disease deterred patients who felt disempowered to take action [49]. Conversely, trusted relationships reassured patients that their 
health will improve. Healthcare providers involving patients and families in the treatment decision-making process tend to stimulate patients' motivation and engagement in the healing process [49].

Losses of loved ones and thinking that there were no solutions stalled patients' engagement in the empowerment process because they considered their situation out of control. Meanwhile, some patients were motivated to control their disease by replacing old habits with new ones favoring recovery. SOC being an interaction between the individual and life context [26-27], feeling supported contributed to patients' motivation in activating and making the best use of their inner assets, which increased their confidence in their ability to manage their condition.

GRR in terms of medicines, equipment, laboratory supplies and personnel are needed for delivering good healthcare. Barriers identified at the hospital/organizational level included the unavailability and/or misuse of resources. The budget allocated to managing NCDs in the healthcare system in Cameroon is awfully low [52], given the $15 \%$ of the national budget recommended in Abudja in 2001 [40]. The lack of health insurance makes patients and families bearing treatment costs in Cameroon, an enduring situation in LMICs $[53]$.

Two-third of patients were women, of whom about half were widows with husbands who died from these diseases or their complications. Over two-third of FCs were women, due to gender norms in Cameroon and elsewhere in LMICs where women remain the primary family caretaker [54].

The influence of belief was positive or negative on patients' empowerment, depending if it was motivational or not to the development of patients' autonomy to self-manage their disease. Believing that the disease was caused by spiritual forces or curse did not allow patients to change their lifestyle which plays a key role in NCDs development, occurrence, and complications; believing in God motivated patients to follow the therapeutic plan. Our findings support previous research showing that health belief plays a role in patient decision through the process of healthcare service [55]. 
Considering patient satisfaction as the patient's positive evaluation of healthcare dimensions, patient experiences with medical staff were influential factors. Patient satisfaction being an indicator of the quality of services [56], the more patients are satisfied the more they will be committed to follow-up services and then develop their ability to self-manage their disease and vice-versa.

\section{Strengths and limitations}

A major strength of this study is its multilevel approach to studying patients' and FCs' experiences and perspectives representing various socioeconomic and cultural backgrounds, with different data collection methods and pertaining to all three levels of a national healthcare services. Another strength is that patients and FCs had unique experiences that informed their opinions on what happened in the national healthcare system; considering patients' and families' recommendations about structural, broader and systemic changes may promote successful patient engagement and outcomes. Finally, these unravelled experiences and perspectives are invaluable to filling missing healthcare gaps in resource-limited settings like Cameroon.

This study was limited to one of the main hospitals in Yaounde, Cameroon; results may not be generalizable across all contexts. However, they may be helpful to the extent they are transferable to similar settings.

\section{Conclusions}

Our multilevel investigation of PE in the management of hypertension and diabetes found that patientsidentified factors mainly related to self-management of the disease while caregivers focused chiefly on factors at organizational/hospital and central levels indirectly related to disease management and beyond their control. The preponderance of patient-level factors compared to those at central/ministry and hospital/organizational levels calls for the need to pay more attention to them in resource-limited settings. Accounting for patient's and families' experiences and opinions may be key to improving healthcare delivery. 


\section{List of abbreviations}

A1C: Glycated hemoglobin

BP: Blood pressure

DALY: Disability-adjusted-life-years

FC: Family caregiver

FGD: Focus group discussion

FPG: Fasting Plasma Glucose

GP: General practitioner

GRR: Generalized resistance resources

HTN: Hypertension

LMIC: Low- and middle-income countries

NCD: Noncommunicable diseases

OGTT: Oral Glucose Tolerance Test

PE: Patient empowerment

PHCDH: Primary healthcare district hospital

QDA: Qualitative Data Analysis

SOC: Sense of coherence

SP: Specialist physician

T2D: Type 2 diabetes 


\section{References}

1. GBD 2017, DALYs, HALE Collaborators. Global, regional, and national disability-adjusted life-years (DALYs) for 359 diseases and injuries and healthy life expectancy (HALE) for 195 countries and territories, 1990-2017: a systematic analysis for the Global Burden of Disease Study 2017. Lancet. 2018;392:1859-1922.

2. Gouda HN, Charlson F, Sorsdahl K, Ahmadzada S, Ferrari AJ, Erskine H, et al. Burden of noncommunicable diseases in sub-Saharan Africa, 1990-2017: results from the Global Burden of Disease Study 2017. The Lancet Global Health. 2019;7:1375-87.

3. Ferrannini E, Cushman WC. Diabetes and hypertension: The bad companions. The Lancet. 2012;380: 601610.

4. Tsimihodimos V, Gonzalez-Villalpando C, Meigs JB, Ferrannini E. Hypertension and diabetes mellitus: coprediction and time trajectories. Hypertension. 2018;71:422-8.

5. Tsolmon U et al. Association of cardio-metabolic risk factors with arterial hypertension. Journal of Hypertension 2021;39:330-331.

6. Fuller JH. Epidemiology of hypertension associated with diabetes mellitus. Hypertension. 1985; 7 Suppl II:3-7.

7. Kuate Defo B, Mbanya JC, Kingue S, Tardif JC, Choukem SP, Perreault S, et al. Blood pressure and burden of hypertension in Cameroon, a microcosm of Africa: a systematic review and meta-analysis of population-based studies. Journal of hypertension. 2019; 37:2190.

8. Bigna JJ, Nansseu JR, Katte JC, Noubiap JJ. Prevalence of prediabetes and diabetes mellitus among adults residing in Cameroon: a systematic review and meta-analysis. Diabetes research and clinical practice. 2018;137:109-18.

9. Saksena P, Xu K, Evans DB. Impact of out-of-pocket payments for treatment of noncommunicable diseases in developing countries: a review of literature. Geneva: World Health Organization, Department of Health Systems Financing. 2011.

10. Bukhman G, Mocumbi AO, Atun R, Becker AE, Bhutta Z, Binagwaho A, et al. The Lancet NCDI Poverty Commission: bridging a gap in universal health coverage for the poorest billion. The Lancet. 2020;396:991-1044.

11. World Health Organization. Framework on integrated, people-centred health services. Geneva: World Health Organization; 2016.

12. World Health Organization. Global action plan for the prevention and control of noncommunicable diseases 2013-2020. Geneva: World Health Organization; 2013.

13. Angelmar R, Bermann BP. Patient empowerment and efficient health outcomes. In: Financing sustainable healthcare in Europe. 2007:139-162. http://www. sustainhealthcare.org/The_Cox_Report.pdf, accessed June $20,2021$. 
14. Carman KL, Dardess P, Maurer M, Sofaer S, Adams K, Bechtel C, et al. Patient and family engagement: a framework for understanding the elements and developing interventions and policies. Health affairs. 2013;32:223-31.

15. Nafradi L, Nakamoto K, Schulz PJ. Is patient empowerment the key to promote adherence? A systematic review of the relationship between self-efficacy, health locus of control and medication adherence. PloS one. 2017;12:0186458.

16. Abrahams N, Gilson L, Levitt NS, Dave JA. Factors that influence patient empowerment in inpatient chronic care: early thoughts on a diabetes care intervention in South Africa. BMC endocrine disorders. 2019;19:133.

17. Johnson LC, Thompson NJ, Ali MK, Tandon N, Chwastiak L, Mohan V. Factors that facilitate patient activation in the self-management of diabetes and depression among participants enrolled in an integrated chronic care model in India. Social Science \& Medicine. 2021;270:113646.

18. Grund J, Stomberg MW. Patients' expectations of the health advice conversation with the diabetes nurse practitioner. J Prim Care Community Health. 2012;3:230-4.

19. Mudge S, Kayes N, McPherson K. Who is in control? Clinicians' view on their role in self-management approaches: a qualitative metasynthesis. BMJ open. 2015;5:007413.

20. Bos-Touwen ID, Trappenburg JC, Van Der Wulp I, Schuurmans MJ, De Wit NJ. Patient factors that influence clinicians' decision making in self-management support: A clinical vignette study. PLoS One. 2017; $12: 0171251$.

21. Mogueo A, Oga-Omenka C, Hatem M, Kuate Defo B. Effectiveness of interventions based on patient empowerment in the control of type 2 diabetes in sub-Saharan Africa: A review of randomized controlled trials. Endocrinology, diabetes \& metabolism. 2021;4:00174.

22. World Health Organization. WHO Guidelines on Hand Hygiene in Health Care: First Global Patient Safety Challenge Clean Care Is Safer Care. Geneva: World Health Organization; 2009.

23. Carver CS, Scheier M. On the self-regulation of behavior. Cambridge: Cambridge University Press; 1998.

24. Deci E, Ryan R. Intrinsic motivation and self-determination in human behavior. New York: Plenum Press; 1985.

25. Bandura A. Social foundations of thought and action : a social cognitive theory. Englewood Cliffs: Prentice-Hall; 1986.

26. Antonovsky AG. Unraveling the mystery of health : how people manage stress and stay well. 1st ed. San Francisco: Jossey-Bass; 1987.

27. Mittelmark MB, Sagy S, Eriksson M, Bauer GF, Pelikan JM, Lindström B, et al. The handbook of salutogenesis. Springer; 2017. 
28. Champion V. The Health Belief Model. In: Glanz K RB, Viswanath K, editors. Health behavior and health education. San Francisco: Jossey-Bass; 2008. p. 45-65.

29. Bishop AC, Baker GR, Boyle TA, NJ MacKinnon. Using the Health Belief Model to explain patient involvement in patient safety. Health Expectations. 2014;18:3019-3033.

30. Linder-Pelz S. Toward a theory of patient satisfaction. Soc Sci Med. 1982;16:577-82.

31. Bowling A, Rowe G, Lambert N, Waddington M, Mahtani KR, Kenten C, et al. The measurement of patients' expectations for health care: a review and psychometric testing of a measure of patients' expectations. Health Technol Assess. 2012;16:30.

32. Afrashtehfar KI, Assery MK, Bryant SR. Patient Satisfaction in Medicine and Dentistry. International Journal of Dentistry. 2020;29:20.

33. World Health Organization. Primary health care systems (PRIMASYS): case study from Cameroon, abridged version. Geneva: World Health Organization (2017).

34. Provalis Research. QDA Miner 5.0. Montreal: Provalis Research (2013).

35. Braun V, Clarke V. Using thematic analysis in psychology. Qualitative research in psychology. 2006;3:77-101.

36. Patton MQ. Qualitative research and evaluation methods. Thousand Oaks. Cal: Sage Publications. 2002.

37. Ratinaud P. IRaMuTeQ 0.7 alpha 2. 2020. http://www.iramuteq.org/ Accessed 05 nov 2020

38. Baril E, Garnier B. IRaMuteQ 0.7 alpha 2: Interface de R pour les Analyses Multidimensionnelles de Textes et de Questionnaires. Institut National d'Etudes Démographiques, Paris (France). 2015.

39. Aikins AD, Boynton P, Atanga LL. Developing effective chronic disease interventions in Africa: insights from Ghana and Cameroon. Globalization and health. 2010;6:1-5.

40. Azevedo MJ. The State of Health System (s) in Africa: challenges and opportunities. In Historical Perspectives on the State of Health and Health Systems in Africa, Volume II. Palgrave Macmillan, Cham. 2017. p. 1-73.

41. Bar S, Grant K, Asuri S, Holms S. British Columbia Ministry of health patients as partners: a transformational approach. In: Healthcare management forum. Los Angeles: SAGE Publications. 2018. p. 51-56.

42. Carman KL, Dardess P, Maurer M, Sofaer S, Adams K, Bechtel C, et al. Patient and family engagement: a framework for understanding the elements and developing interventions and policies. Health affairs.

2013;32:223-31.

43. Castro EM, Van Regenmortel T, Vanhaecht K, Sermeus W, Van Hecke A. Patient empowerment, patient participation and patient-centeredness in hospital care: a concept analysis based on a literature review. Patient education and counseling. 2016;99:1923-39. 
44. Kane J, Landes M, Carroll C, Nolen A, Sodhi S. A systematic review of primary care models for noncommunicable disease interventions in sub-Saharan Africa. BMC family practice. 2017;18:12.

45. Lall D, Engel N, Devadasan N, Horstman K, Criel B. Models of care for chronic conditions in low/middle-income countries: a 'best fit' framework synthesis. BMJ Global Health. 2018;3:001077.

46. Pomey MP, Ghadiri DP, Karazivan P, Fernandez N, Clavel N. Patients as partners: a qualitative study of patients' engagement in their health care. PloS one. 2015;10:0122499.

47. Sama M, Nguyen VK. Governing health systems in Africa. African Books Collective. 2008.

48. Fumagalli LP, Radaelli G, Lettieri E, Masella C. Patient empowerment and its neighbours: clarifying the boundaries and their mutual relationships. Health Policy. 2015;119:384-94.

49. Náfrádi L, Kostova Z, Nakamoto K, Schulz PJ. The doctor-patient relationship and patient resilience in chronic pain: A qualitative approach to patients' perspectives. Chronic illness. 2018;14:256-70.

50. Bos-Touwen ID, Trappenburg JC, Van Der Wulp I, Schuurmans MJ, De Wit NJ. Patient factors that influence clinicians' decision making in self-management support: A clinical vignette study. PLoS One. 2017;12:0171251.

51. Orrego C, Ballester M, Perestelo L, Sunol R. Patient empowerment as a promising avenue towards health and social care integration: results from an overview of systematic reviews of patient empowerment interventions. International Journal of Integrated Care. 2016;16:6.

52. Ministry of Public Health (MPH). Health Sector Strategy 2017-2026. Cameroon: MPH. 2017.

53. Saksena P, Xu K, Evans DB. Impact of out-of-pocket payments for treatment of noncommunicable diseases in developing countries: a review of literature. Geneva: World Health Organization, Department of Health Systems Financing. 2011.

54. Weber AM, Cislaghi B, Meausoone V, Abdalla S, Mejía-Guevara I, Loftus P, et al. Gender norms and health: insights from global survey data. The Lancet. 2019;393:2455-68.

55. Glanz K, Bishop DB. The role of behavioral science theory in development and implementation of public health interventions. Annual review of public health. 2010;31:399-418.

56. Worthington C. Patient satisfaction with health care: Recent theoretical developments and implications for evaluation practice. The Canadian Journal of Program Evaluation. 2005;20:41. 
Table 1. Participants' characteristics

\begin{tabular}{|c|c|c|c|c|}
\hline \multicolumn{2}{|c|}{ Characteristics } & \multicolumn{3}{|c|}{ Participants: n (\%) } \\
\hline & & Patients & Family caregivers & Total \\
\hline Overall & & $23(57.5)$ & $17(42.5)$ & $40(100.0)$ \\
\hline \multirow[b]{2}{*}{ Inpatient } & Yes & $5(21.7)$ & $5(29.4)$ & $10(25.0)$ \\
\hline & No & $18(78.3)$ & $12(70.6)$ & $30(75.0)$ \\
\hline \multirow{3}{*}{ Disease } & Hypertension only & $8(34.8)$ & $4(23.5)$ & $12(30.0)$ \\
\hline & Diabetes only & $6(26.1)$ & $6(35.3)$ & $12(30.0)$ \\
\hline & Hypertension and diabetes & $9(39.1)$ & $7(41.2)$ & $16(40.0)$ \\
\hline \multirow{2}{*}{$\begin{array}{l}\text { Patient's number of years } \\
\text { with the disease }\end{array}$} & $<5(1-4)$ & $10(43.5)$ & -- & $10(43.5)$ \\
\hline & $\geq 5(5-30)$ & $13(56.5)$ & -- & $13(56.5)$ \\
\hline \multirow{2}{*}{$\begin{array}{c}\text { Caregiver's years of caring } \\
\text { for the patient }\end{array}$} & $<5(1-4)$ & -- & $11(64.7)$ & $11(64.7)$ \\
\hline & $\geq 5(5-10)$ & -- & $6(35.3)$ & $6(35.3)$ \\
\hline \multirow[b]{2}{*}{ Sex } & Female & $17(74.0)$ & $12(70.6)$ & $29(72.5)$ \\
\hline & Male & $6(26.0)$ & $5(29.4)$ & $11(27.5)$ \\
\hline \multirow{4}{*}{ Age } & $<30(22-30)$ & -- & $3(17.6)$ & $3(7.5)$ \\
\hline & $\geq 30(30-64)$ & -- & $14(82.4)$ & $14(35.0)$ \\
\hline & $<60(46-59)$ & $7(30.4)$ & -- & $7(17.5)$ \\
\hline & $\geq 60(60-86)$ & $16(69.6)$ & -- & $16(40.0)$ \\
\hline \multirow{4}{*}{ Education } & None & $12(52.2)$ & $2(11.8)$ & $14(35.0)$ \\
\hline & Elementary & $6(26.1)$ & $2(11.8)$ & $8(20.0)$ \\
\hline & Secondary & $3(13.0)$ & $3(17.6)$ & $6(15.0)$ \\
\hline & University & $2(8.7)$ & $10(58.8)$ & $12(30.0)$ \\
\hline
\end{tabular}




\begin{tabular}{|c|c|c|c|c|}
\hline \multirow{16}{*}{ Profession } & Housewife & 8 & 2 & 10 \\
\hline & Trader/businessperson & 5 & 2 & 7 \\
\hline & Teacher & 2 & 2 & 4 \\
\hline & Farmer & 2 & - & 2 \\
\hline & University student & - & 5 & 5 \\
\hline & Pastry chef & 1 & - & 1 \\
\hline & Dressmaker & - & 2 & 2 \\
\hline & Healthcare provider & 1 & 1 & 2 \\
\hline & Manager & - & 1 & 1 \\
\hline & Carpenter & 1 & - & 1 \\
\hline & Artist & - & 1 & 1 \\
\hline & Civil servant & 1 & - & 1 \\
\hline & Biomedical technician & - & 1 & 1 \\
\hline & Human Resource Director & 1 & - & 1 \\
\hline & Retired & 8 & 1 & 9 \\
\hline & Secretary & 1 & - & 1 \\
\hline \multirow{4}{*}{ Marital status } & Married & $14(60.9)$ & $10(58.8)$ & $24(60.0)$ \\
\hline & Single & -- & $7(41.2)$ & $7(17.5)$ \\
\hline & Divorced & $2(8.7)$ & -- & $2(5.0)$ \\
\hline & Widowed women & $7(30.4)$ & -- & $7(17.5)$ \\
\hline \multirow{4}{*}{$\begin{array}{l}\text { Caregiver's relationship with } \\
\text { the patient }\end{array}$} & Daughter, n (\%) & -- & $9(52.9)$ & $9(52.9)$ \\
\hline & Son, n (\%) & -- & $4(23.5)$ & $4(23.5)$ \\
\hline & Wife, n (\%) & -- & $3(17.7)$ & $3(17.7)$ \\
\hline & Grandson, $\mathrm{n}(\%)$ & -- & $1(5.9)$ & $1(5.9)$ \\
\hline
\end{tabular}




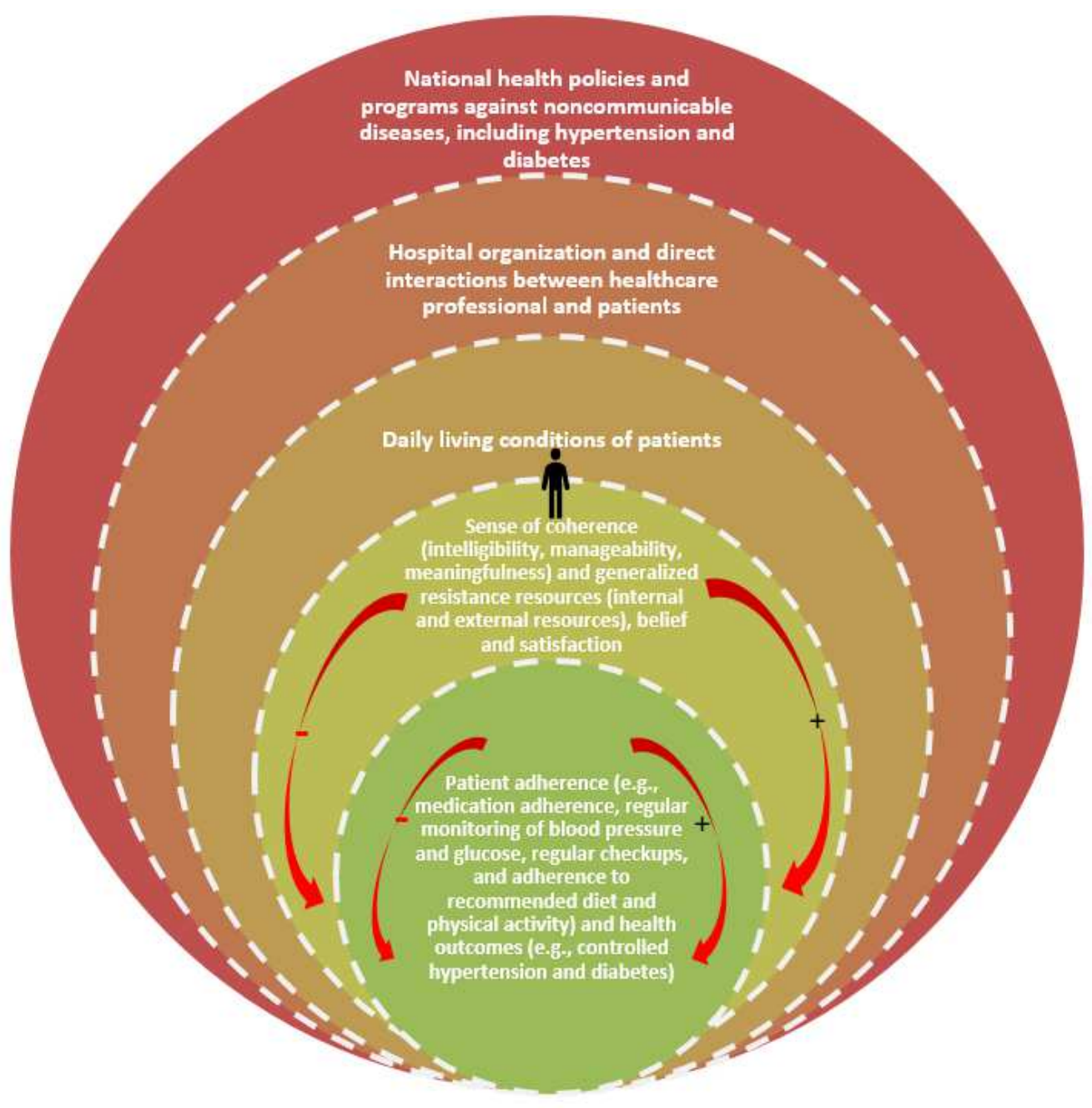

Figure 1. An integrated framework for understanding barriers and facilitators linked to patient empowerment in the management of hypertension or diabetes 


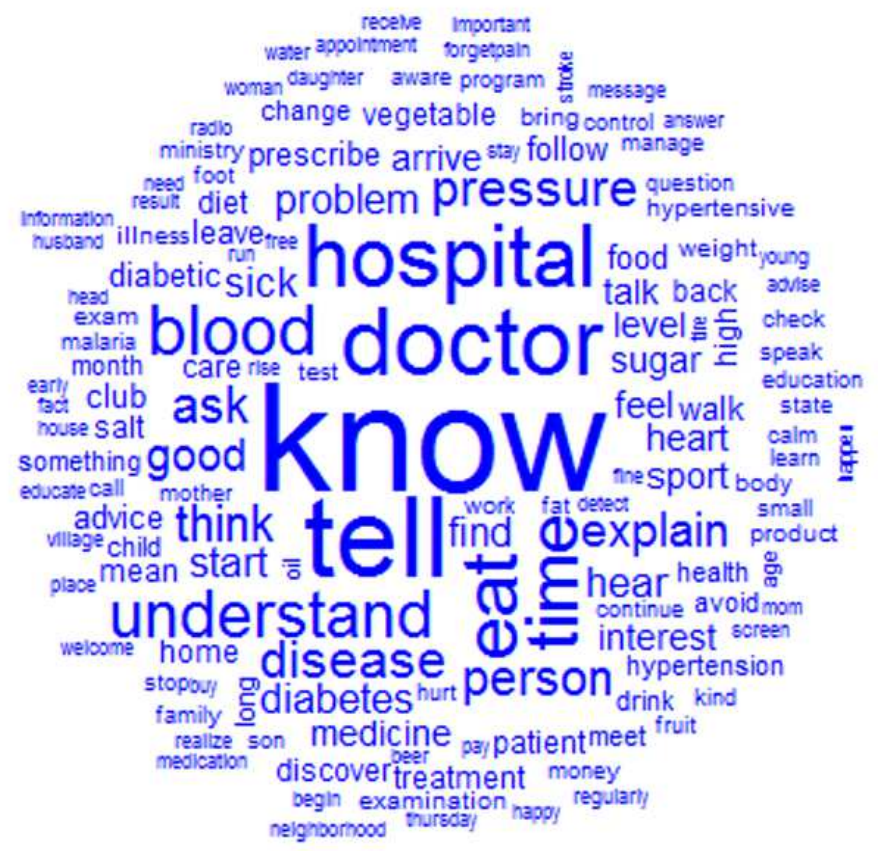

Figure 2: Words used to describe the intelligibility with their frequencies correlating to their size

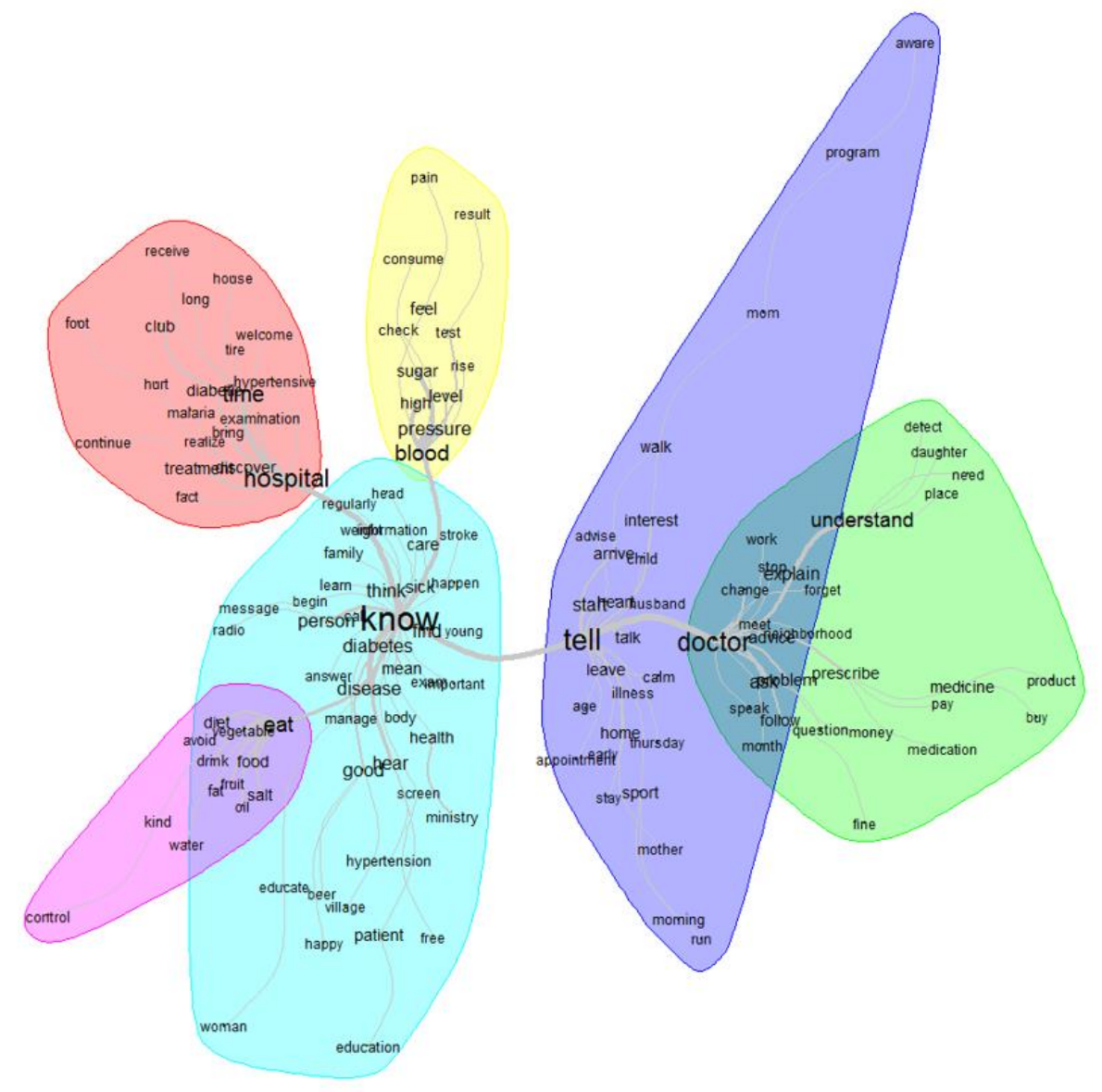

Figure 3: Similarities and links between the different words used to describe the intelligibility 


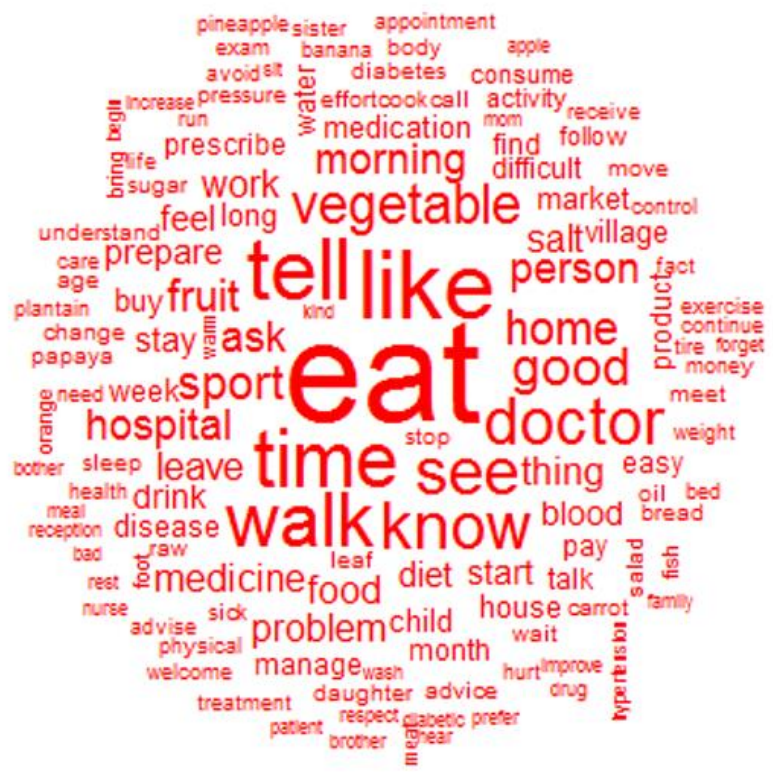

Figure 4: Words used to describe the manageability with their frequencies correlating to their size

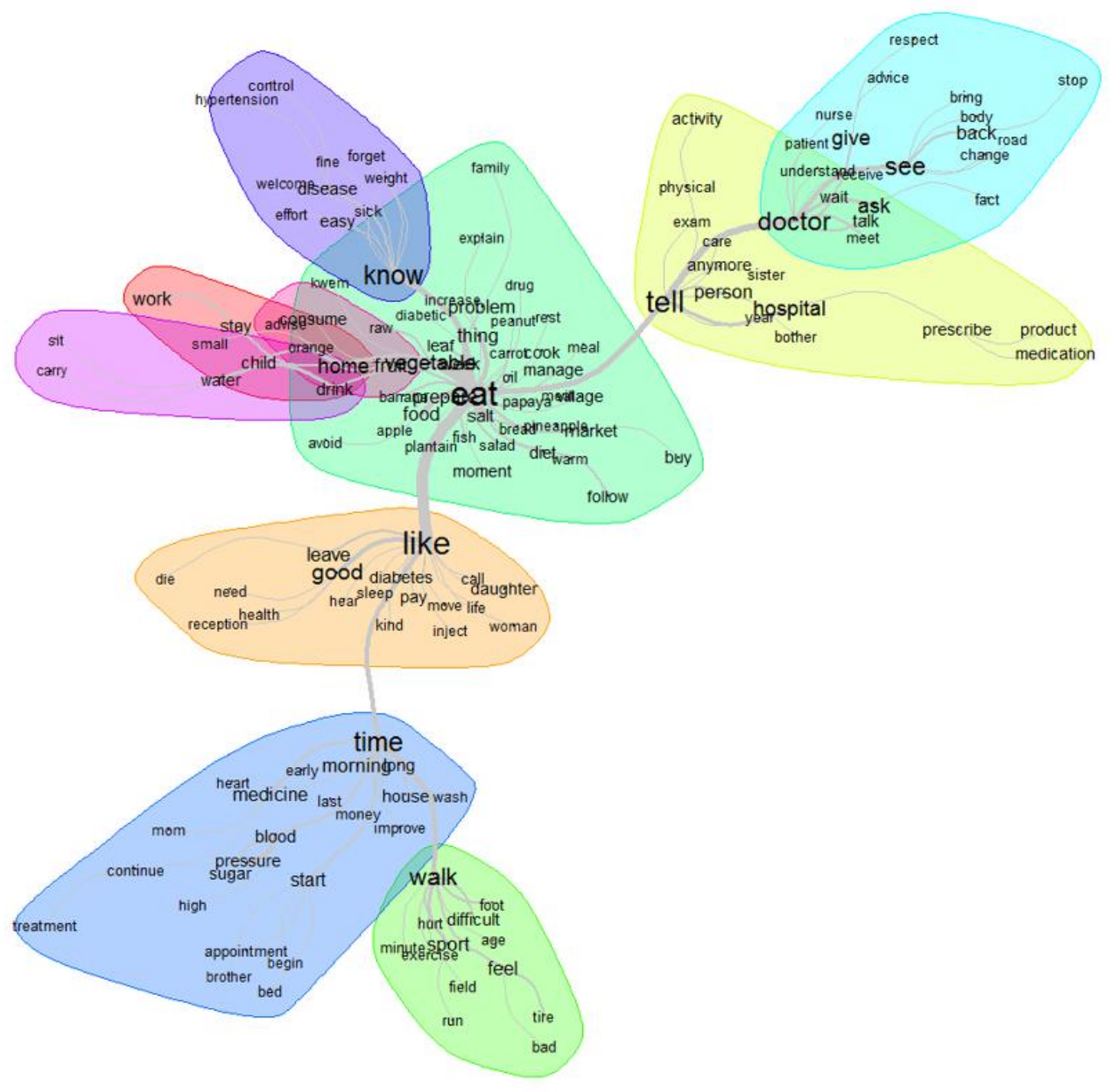

Figure 5: Similarities and links between the different words used to describe the manageability 


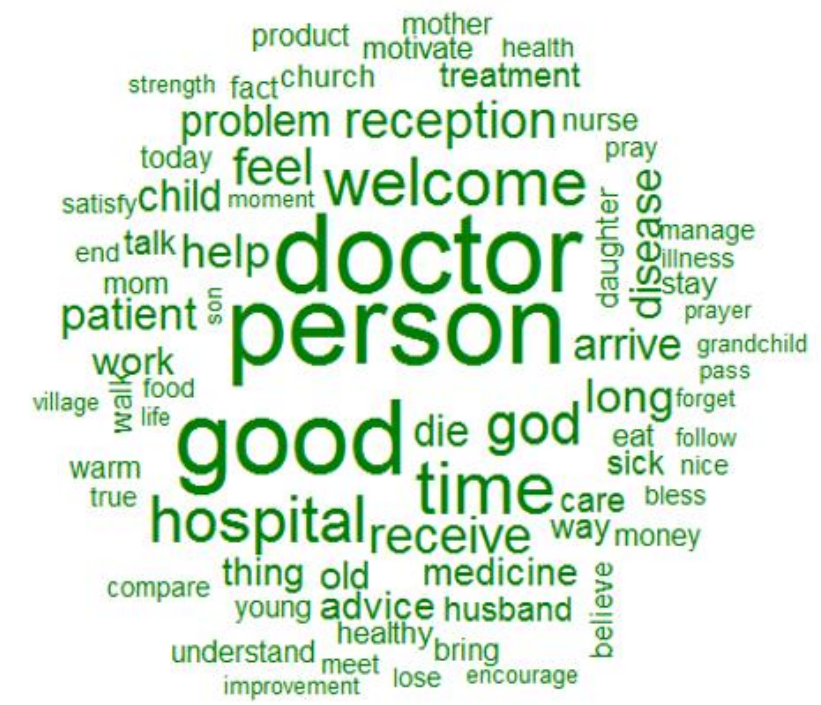

Figure 6: Words used to describe the meaningfulness with their frequencies correlating to their size

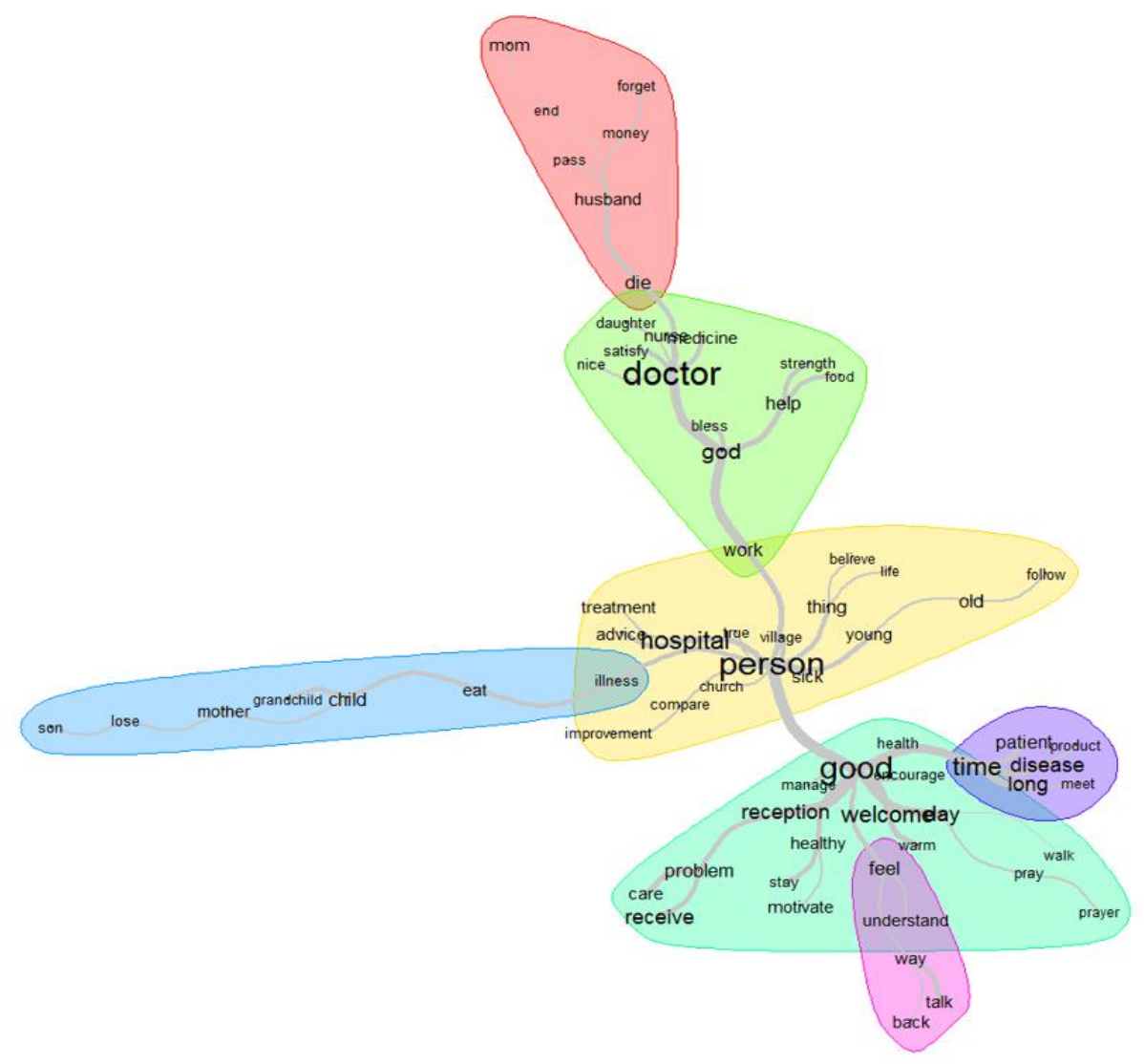

Figure 7: Similarities and links between the different words used to describe the meaningfulness 


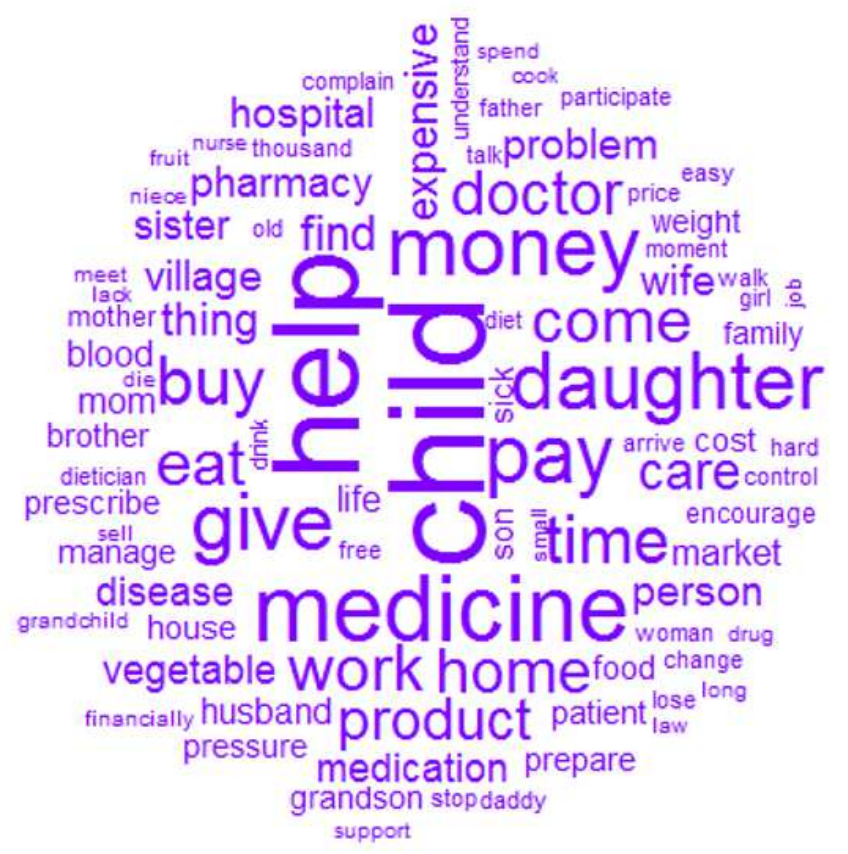

Figure 8: Words used to describe the resources with their frequencies correlating to their size

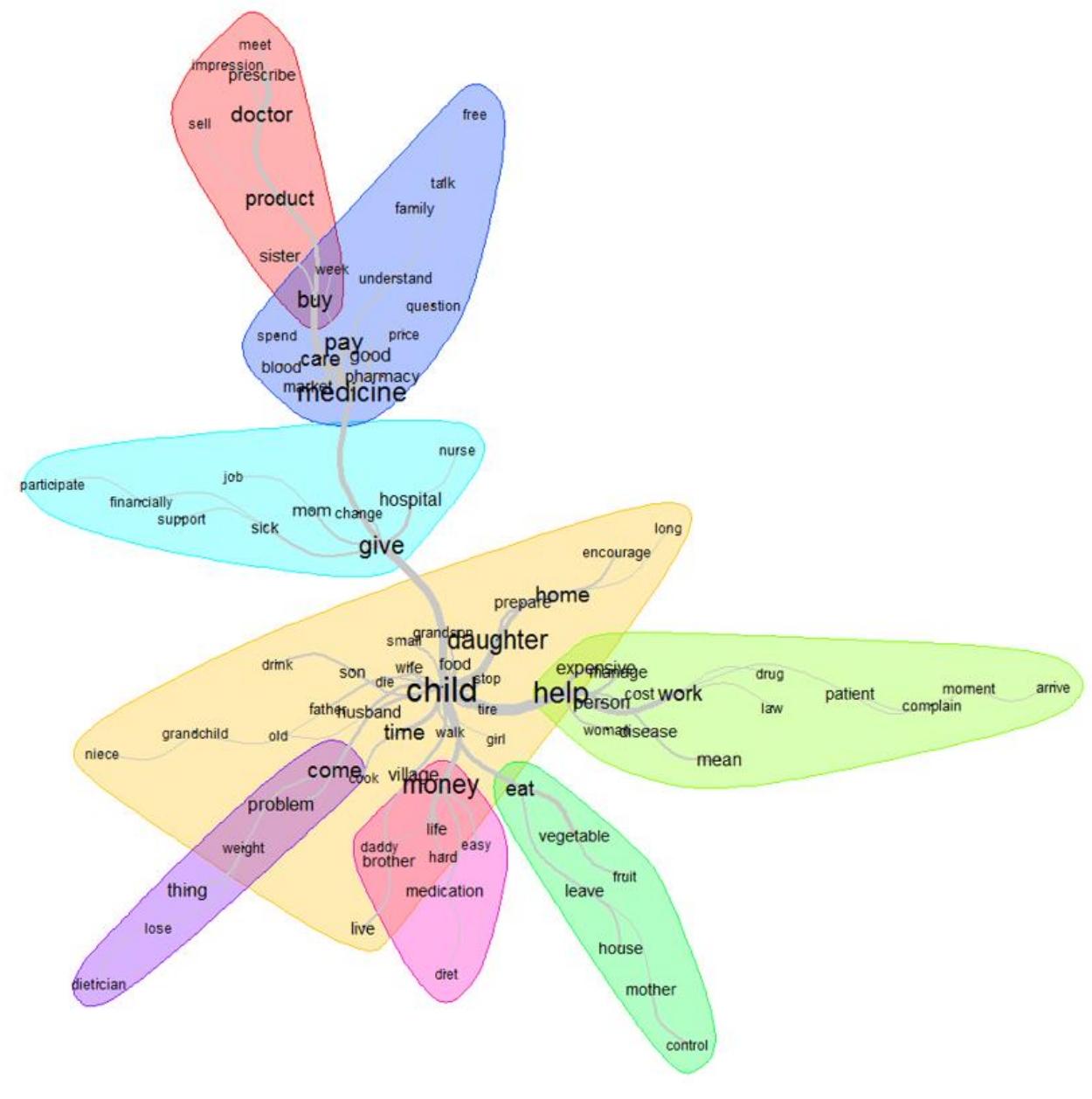

Figure 9: Similarities and links between the different words used to describe the resources 


\section{Ethics approval and consent to participate}

The study was submitted to Institutional Review Boards of the University de Montreal, Canada and the Cameroon National Ethics Committee; it was approved Institutional Review Boards of the University de Montreal, Canada (No. 17-147-CERES-D) and the Cameroon National Ethics Committee (No. 2018061053

CE/CNERSHISP). All procedures performed in the study were in accordance with the ethical standards of these institutions as well as with the 1964 Helsinki declaration and its later amendments or comparable ethical standards.

Participation in the study was voluntary. Informed consent was obtained from all individual participants included in the study. The interviewer obtained informed consent by a written signature from participants prior to each interview. To ensure data confidentiality and anonymity, data were anonymized and irreversibly de-identified to protect patients, healthcare providers and hospital privacy.

\section{Acknowledgements}

We would like to thank all the people who contributed or facilitated the data collection for carrying out this study in Cameroon. Special thanks to all the patients and their family caregivers who, despite the difficulties linked to their illness, accepted, and found time to share with us their experiences with their diseases. Their enthusiasm and generosity to contribute to this research by giving us the maximum information to the best of their knowledge were special and deserve to be highlighted and thanked. We also thank the decision-makers at the hospital and at the Ministry of Health, for their availability and generosity in sharing information about the management of chronic and noncommunicable diseases in Cameroon. Thanks to all the healthcare providers - nurses, general and specialist physicians -, for their availability and dedication to their patients, and their generosity in sharing information about the organization and delivery of healthcare to patients who have hypertension or diabetes. 


\section{Authors' contributions}

AM and BKD conceived of the study and designed it. AM did the data collection. Both authors wrote the manuscript and approved its final version. The two authors have contributed equally to this work and share first authorship.

\section{Funding}

This research was supported by the Fonds de recherche du Québec - Société et culture (FRQSC) (Canada) and by the Program in Transnational, Subnational, National and Continental Population, Nutrition and OneHealth (PRONUSTIC), University of Montreal (Canada).

\section{Competing interests}

The authors declare that they have no competing interests.

\section{Availability of data and materials}

All data generated or analysed during this study are included in this published article [and its supplementary information files].

\section{Consent for publication}

Not applicable. 


\section{Supplementary Files}

This is a list of supplementary files associated with this preprint. Click to download.

- 20210ct11BMCHSRPatientsCaregiverssExperiencesPerspectivesonFactorsaffectingPESuppfiles.pdf 